\title{
BRIEF REVIEW OF GERMAN STANDARDS FOR QUALITY AUDITS IN AUTOMOTIVE PRODUCTION
}

\author{
Yulia Šurinová $^{1 *}$, Katarína Lestyánszka Škưrková ${ }^{1}$ \\ ${ }^{1}$ Institute of Industrial Engineering, Management and Quality, Slovac University of Technology, Faculty \\ of Materials Science and Technology, Paulinská 16, 91724 Trnava \\ * corresponding author: Tel.: +421 948 525768, e-mail: yulia.surinova@stuba.sk
}

\begin{abstract}
Resume
Quality management systems (QMS) in the automotive industry have several differences in comparison with other industrial factories. Each customer has his own specific requirements, the so-called CSRs (Customer Specific Requirements). Audits are one of the core-tools of quality management to make the PDCA cycle work. It is clear that compliance to ISO/TS 16949:2009 requirements is a condition for supplying the automotive industry. But there are some standards which co-exist together with the official ISO9001 Q-management systems standards and technical specification ISO/TS16949. What are those specific standards in the automotive industry and which standard should be used and why those are the questions to be answered in this article.
\end{abstract}

\author{
Article info \\ Article history: \\ Received 20 September 2013 \\ Accepted 25 November 2013 \\ Keywords: \\ Quality management system, \\ automotive production, \\ customer specific requirements, \\ audit
}

\section{Introduction}

In the times of economic dumping each vehicle maker does his best to effectively manage his internal and external processes. It finally leads to creation of their specific requirements for suppliers. It has become not enough to build the quality management system according to ISO 9001:2008, not even enough to meet the requirements of ISO TS 16 949:2009 which were created specially for the automotive production. It is important nowadays to meet the specific requirements of each customer (ŠURINOVÁ Y., 2011). Different customers create their specific requirement based on their special market strategy in order to satisfy customers needs better than other competitive organizations do. These special requirements are often based on the manuals of American quality management standards QS 9000 or German standards for quality management VDA. Globalization brings to the world of business the best improvement tools and methods which have been created in different countries and companies in the world (ŠURINOVÁ Y., 2011).
2. Description of the approach, work methodology, materials descriptions

There is no doubt that there are plenty of customer specific requirements in the automotive production. Even in the field of quality audits it would seem that some customers do not know what they want. In the automotive production ISO/TS 16949 certification is required, on the other hand, there are VDA standards which are required by German companies.

The hypothesis of the study is: VDA6 series should be treated as a customer specific requirement which can bring excellence to organizations.

The related standards review and literature search is the main tool used in this article. The core job was performed while reviewing the VDA6 series standards requirements and the ISO/TS16949:2009 requirements. To make conclusions, the information available in the article was verified in various Slovak automotive supplying organizations. 


\section{VDA6 series review}

Increasing requirements in the automotive production make organizations change and continuously improve the quality management system. The German automotive industry is recognized from all sides as having successfully followed a premium strategy - developing brands which stand for high performance and high quality and production values. The aim of VDA standards creation is reaching Automotive Excellence (VDA 6, 2006).

Comparing VDA 6 series and ISO 19011:2011 it is evident that VDA 6.x standards are more specific with their requirements. VDA 6 standards give us concrete formulas how to determine the audit range, how to quantify the analyzed system /process efficiency, what requirements should the auditor meet to perform a concrete audit.

It is also true that some of the VDA6 series standards indicate an evaluation system which sets the rules how to quantify the way the analyzed process or system meets the requirements. It is indisputably the case of quality quantification.

Different standards of the VDA6 series have each their own evaluation criteria. Questionnaires (for VDA 6.1 and VDA 6.3) or process signs (for VDA 6.7) may serve as an example of audit criteria. Each of these standards has also its own evaluation formulas, which help to quantify meeting the requirements of the VDA 6.2 process /system which was created for auditing services in automotive sites.

Further on, the most widely used standards VDA 6.1 and VDA 6.3 will be reviewed.

\subsection{VDA 6.1 Quality management system audit}

VDA 6.1 is the first standard of the VDA 6 series. According to Štetinová, this is a special standard which has added some special fieldspecific requirements for quality management systems audit and has some special features in comparison with ISO 9001. VDA6.1 provides a questionnaire for assessing a company's quality system (KLAUS J. ZINK, 1998).

Regarding contents, it substantially covers all elements of ISO 9001 and partly goes beyond them. Comparing ISO 9001 and VDA 6.1, there are some specific areas in VDA6.1 which are not covered in ISO 9001.

VDA 6.1 has been valid since 1998. Since April, 1st 1999 this standard has been used as obligatory for all German automobile producers. The aim of this standard is to make the automobile producers continuously improve their processes, prevent problems occurrence, eliminate critical factors in production systems and others. The standard was based on ISO 9001:1994 and was later revised in 2003 (ŠTETINOVÁ A., 2005). This standard has not been revised according to the ISO 9001:2008 due to the fact that registration to ISO/TS 16949 is now accepted instead of VDA 6.1.

Admittedly, this is the first tentative conclusion that VDA6.1 audits standard used to be widely implemented in automotive production, but in the light of this fresh research, we must conclude that it tends to be replaced by ISO/TS 16949 general specification for quality management in the automotive branch.

\subsection{VDA 6.3 Process audit for mass produc- tion}

VDA 6.3 is an excellent tool for process audits within the automotive industry acting as a guideline for performing audits. According to Cameron, 2011 it provides information on the significance and application scope of a process audit over the entire product realization cycle. It defines the audit process, the criteria for evaluation of the process audit results and the requirements of the processes. At the heart of the standard, each step in the process is modeled with six links and is governed by the Deming Loop - Plan Do Check Act. There are three grades that an organization can reach under VDA $6.3-A$, B \& C. This means that an organization can pass the audit but still has the scope for further improvement (CAMERON, 2011).

It is clear that VDA 6.3 defines a process based audit standard for evaluating and improving controls of processes in a manufacturing organization. In order to continuously monitor and improve processes in organizations and to secure process reliability VDA 6.3 was designed. Together with VDA 6.1 and other VDA6 series standards it may be treated as a customer specific requirement of the European (German) automobile producers. The VDA 6.3 standard was designed in 1998 and was revised in 2010.

Production Engineering Archives 1 (2013) 
The standard was revised in order to follow changing environment in automotive production. Process risks and weaknesses as well as interactions between processes have to be followed. In other words, revised in 2010, the standard was comprehensively restructured to reflect the changes to ISO 9001:2008 and customer specific requirements in the automotive industry.

The revised VDA 6.3 supports process approach and thus is still widely used to perform audits of suppliers. This standard includes a questionnaire for each audit phase. It also contains an evaluation system which provides a formula how to evaluate standard requirements fulfillment. Besides, there is a supplier categorization matrix included in VDA 6.3.

The standard can be used by any organization, either for internal process audits or for evaluating potential or existing suppliers. Compliance to VDA 6.3 is mandated by some vehicle makers and encouraged by others. VDA 6.3 provides an opportunity to master some of the tools and approaches that have helped make this success possible. VDA 6.3 is particularly useful for a prime mover in any sector who wants to follow a premium strategy and wants to ensure that the supply chain is capable of supporting this approach to global competitiveness (CAMERON L., 2011).

\section{Description of achieved results}

We have made it absolutely clear that VDA6s series have some benefits in comparison with ISO/TS 16949. In fact VDA standards set some further requirements for automotive suppliers. However, VDA6.x can be treated as a customer specific requirement and must be applied if there is a customer's special requirement.

Despite those arguments, the fact still remains that ISO/TS 16949:2009 is the only quality management standard for automotive production which is recognized and accepted by each vehicle maker all over the world. The VDA6.x standards are usually required by German organizations and are co-integrated with ISO/TS 16949 requirements.

\section{Conclusions}

The ISO/TS 16949 standard is a highly efficient standard, not a system of implementation of quality management and auditing, nevertheless there are some commonly known and used in practice standards which can help organizations perform the audits according to the verified and validated special formula (VDA6.x are the examples of such standards).

\section{Acknowledgements}

This work paper has been supported by the project VEGA 1/1203/12 "Information quality management within project management in industrial organizations in $S R ”$.

\section{References}

[1] CAmeron, L.: VDA 6.3 Process Audit - an indepth manufacturing process audit tool in SMMT Industry Forum 2011 online http://www.industryforum.co.uk/articles/vda-63-process-audit/

[2] KLAuS J. ZinK, Voss, V.: Quality in Germany an overview in The TQM Magazine, Vol. 10 Iss: 6 , pp.458 - 463

[3] ŠURINOVÁ, Y., PAUlovÁ, I.: Globalization effects on customer specific requirements in automotive production in VedecképráceMtF STU. Research papers Faculty of Materials Science and Technology Slovak University of Technology in Trnava Vol. 18, č. 28.s. 101106. ISSN 1336-1589.

[4] ŠtetinovÁ, A., Hulín, P.: What is VDA 6.1? inLogistický monitor ISSN 1336-5851

[5] VDA 6 Quality audits - basics. 4nd edition 2006

[6] VDA 6.1 - Quality system audit, $4^{\text {th }}$ revised edition 2003, up-dated reprint 2010

[7] VDA 6.2 - Quality System Audit - Services . Vomule 6, Part 2, 2nd edition 2004

[8] VDA 6.3 Process audit. Volume 6, Part 3, 2nd edition June 2010, 2nd completely revised edition

[9] VDA 6.7 Process audit for single production. Volume 6 Part 7, 1st edition 2005.

[10] Ulewicz R., Dima I.C., Grabara J. 2013, Quality Assurance in the Process of Material Selection and Production of Semitrailer Structure Parts. Metalurgia International Vol.18 nr 7, pp. 195-199 